\title{
Fact and Law in the Causal Inquiry
}

\begin{abstract}
Alex Broadbent
This is a post-peer-review but pre-copy-edited version of a paper due to be published in the journal Legal Theory, 2009, 15(3).
\end{abstract}

\begin{abstract}
This paper takes it as a premise that a distinction between matters of fact and of law is important in the causal inquiry. But it argues that separating factual and legal causation as different elements of liability is not the best way to implement the fact/law distinction. It is partly a legal question what counts as a cause-in-fact; and certain liabilitylimiting doctrines under the umbrella of "legal causation" depend on the application of factual-causal concepts. The contrastive account of factual causation proposed in this paper improves matters. This account more clearly distinguishes matters of fact from matters of law within the cause-in-fact inquiry. It also extends the scope of cause-in-fact to answer some questions currently answered by certain doctrines of legal causation - doctrines which, it is argued, are more naturally seen as applications of our ordinary causal concept than as non-causal liabilitylimiting devices.
\end{abstract}

\section{The Fact/Law Distinction}


There are good reasons for legal process to distinguish questions of fact from questions of law: for example, clarity of reasoning, justice, and common sense. The latter suggests that, if a question before a court is one of fact, it is to be answered by evidence, and sound inferences from the evidence. Whereas if it is one of law, it is to be answered by statute, precedent, and policy, to the satisfaction of an expert in those things - which usually means a judge.

It may not always be possible to entirely separate questions of fact from questions of law. Many "objective" legal tests mix the questions in quite complex ways. For example, reasonable foreseeability is a legal doctrine which aims to capture an objective fact about what a reasonable person would foresee; yet a lawyer will be better able to predict what a court will consider reasonably foreseeable than the man on the Clapham omnibus. For another example, what courts call findings of fact are governed by admissibility and relevance of evidence, as well as standards of proof and inference, which are all matters of law. Nevertheless, the distinction between law and fact remains of great importance in certain contexts. It is central to the deployment of juries and to the jurisdiction of appellate courts. And it is fundamental to the proof of any given proposition. There is no point trying to prove that the gun belonged to Bloggs by citing authority, and no point producing fingerprints from the gun if you are trying to prove that title passes by a contract for the sale of goods which is voidable for misrepresentation. The present essay is premised on the view that the distinction between matters of fact and matters of law is important in legal practice at least sometimes, even if a universal and sharp theoretical distinction is hard to defend. 
One context where the distinction between law and fact has been considered important is the causal inquiry, that is, the effort to establish whether a given harm was caused by the defendant's wrongful action. Overwhelmingly, the fact/law distinction has been translated into the context of the causal inquiry in one, simple way. Matters of causal fact belong under the head of factual causation. This is the element of liability consisting in a causal nexus between wrong and harm. Matters of law are distributed across other elements of liability. Those pertaining directly to the causal nexus, and in particular limiting its legal relevance, may be grouped together under the umbrella of legal causation, which I use in its broadest sense to cover such doctrines as novus actus interveniens, remoteness of damage (in the English jurisdiction), and (in the American jurisdiction) proximate cause.

Implementing the fact/law distinction in the causal inquiry by distinguishing between factual-causal and legal-causal elements of liability is an obvious strategy, with the merit of simplicity. It is the favoured, indeed the only, approach of those who believe there exists an important fact/law distinction to be made in the causal inquiry. Thus Richard Wright argues that:

...much of the disagreement and confusion in the debates about causation stems from failures to distinguish the causal inquiry from other elements of the courts' liability... some writers attribute to the causal inquiry issues that are properly associated with the tortious-conduct or proximate-cause inquiries. 
Conversely, other writers trivialize the causal inquiry by linking it to the actor's conduct as a whole... ${ }^{1}$

On the picture Wright goes on to advocate, the causal inquiry concerns facts, and facts only:

...the causal inquiry is a factual, empirical inquiry that can be - and almost always is - kept distinct from the policy issues in tort adjudication. ${ }^{2}$

If the first part of the proposed distinction is correct, then presumably the causal inquiry can be distinguished from legal issues more generally; precedent and statute are presumably no more relevant than policy to settling "factual, empirical" questions. Wright's view, then, is that there is a sharp distinction between matters of fact and matters of law at least when it comes to the causal inquiry; further, that this distinction is important; and finally, that it ought to be (and in practice usually is) implemented by a sharp distinction between factual causation and other, non-causal aspects of liability.

This paper explores a different line, accepting, with Wright, that a strong fact/law distinction is important in the causal inquiry, but denying that it should be implemented by a corresponding distinction between elements of liability. I will argue (Sections 2 and 3) that law cannot be kept out of the factual causation element of liability, and conversely (Section 4) that properly causal considerations underlie some

\footnotetext{
${ }^{1}$ Richard Wright, Causation in Tort Law, 73 CALIFORNIA LAW REVIEW 1735-1828, 1740 (1985).

${ }^{2} I d$. at 1803 .
} 
of the doctrines of legal causation. Accordingly, the account of factual causation proposed (in Section 5) explicitly gives the law a place in determining what counts as cause in fact. To a Wright-sympathiser, this strategy might sound a bit like appeasement, giving ground to evil forces in the hope that we can control them. But if the negative argument of the paper is correct, then the evil forces are already here: whether the element of liability called factual causation is satisfied is not purely a "factual, empirical" matter. It is in part a matter of law, and calling it factual causation does not change that. Moreover, there seems to be no way to purge factual causation of its legal parts. So it turns out that the only way to preserve the distinction between fact and law in the causal inquiry is to attempt to distinguish the legal from the strictly factual parts of that element of liability misleadingly called "factual causation", and in so doing, admit that it contains legal parts.

The view that the distinction between fact and law is important in the causal inquiry may be challenged, of course. This paper is not meant to answer such a challenge. Rather, it sets out a way of implementing the distinction. In particular I shall focus on a context where others have already considered the distinction important and tried to implement it - namely, in the causal inquiry in tort law. For convenience I will restrict my attention to the tort of negligence in English law, though I see no principled reason why the arguments could not be generalised to the causal inquiry in other areas of English law and to some other jurisdictions, notably the American.

\section{Factual Causation as an Element of Liability}


In this section I present an argument to the effect that satisfaction of the element of legal liability known as factual causation cannot be a purely factual matter: the law plays a crucial role. The problem is not the general doubt previously alluded to, as to whether fact and law can ever be distinguished. Rather, it arises from the particular difficulty of saying what causation is, which necessitates the involvement of legal devices in resolving certain awkward causal puzzles.

Let us use the term purist for somebody who thinks that the fact/law distinction ought to be implemented in the causal inquiry by distinguishing a purely factual-causal element of liability. We have already mentioned Richard Wright, who is an obvious example of a purist. Naturally enough, Wright reasons that without a clear account of factual causation, confusion is bound to follow, and has actually beset some legal theorists (such as Wex Malone, H.L.A. Hart and Tony Honoré). Accordingly, Wright's strategy is to provide a clear account of factual causation. According to Wright's NESS account of causation (and hence of the cause-in-fact element of liability), a cause is a necessary part of a sufficient condition for its effect, with no presumption that the cause should be sufficient or that the sufficient condition should be necessary. The debt to the philosopher Jonathan Mackie's INUS account of causation in the objects is obvious. ${ }^{3}$

I have two objections to Wright's approach. First, his strategy is philosophically naïve (even if his analysis is philosophically respectable). Wright wants to defend purism about the factual-causal element of liability by providing an adequate account of causation itself. But this approach radically underestimates how difficult it is to

\footnotetext{
${ }^{3}$ John MACKIE, The CEMENT OF THE UnIVERSE (1974).
} 
provide a satisfactory account of causation itself. Richard Fumerton and Ken Kress have provided a thorough critique of Wright's NESS analysis, and they point out that the failure of Wright's account is no surprise: "Philosophers have labored long and hard on the question of how to analyze causation, with a striking lack of success". ${ }^{4}$ think the lesson, which Fumerton and Kress do not really explore, is that a defender of the fact/law distinction ought not to adopt Wright's heroic strategy. It would be better to seek a more direct way of distinguishing the fact/law distinction in the causal inquiry, without shouldering the Herculean philosophical burden of saying exactly what the causal facts are.

My second doubt about Wright's approach concerns the central idea that an element of legal liability can consist purely in a causal fact. On closer inspection, making sense of this claim proves tricky. There seem to be some fundamental difficulties with the idea that there can be a purely factual-causal element of liability. The basic trouble is that the obstacles to a good philosophical account of causation also turn out to be obstacles to developing a universally applicable legal test for causation. The law gets round the obstacles by applying different tests in different circumstances, along with a healthy dose of common sense. While this may be a perfectly acceptable procedure in legal practice, it undermines purism about the factual causation element of liability, because the law retains a central role in determining which test is to be applied. This second worry is therefore linked to the first: it arises because we do not have an unproblematic analysis of, or test for, causation, meaning that the law has to step in to make up for the deficiencies. So however much we might feel inclined to insist that

\footnotetext{
${ }^{4}$ Richard Fumerton \& Ken Kress, Causation and the law: preemption, lawful sufficiency and causal sufficiency, 64 LAW AND CONTEMPORARY PROBLEMS 83-105, $102(2001)$.
} 
causal facts do not depend on our human laws, satisfaction of the cause-in-fact element of legal liability nevertheless does depend on our laws: and in this sense, it is never a purely factual matter.

This problem is readily illustrated in cases of causal redundancy. These are cases where a cause is redundant with respect to an effect, such that the effect would have occurred even if the cause had not. ${ }^{5}$ Causal redundancy thwarts the most widely used test for causation, the but-for test. ${ }^{6}$ Assassin A shoots at the Queen, and the Queen dies. Common sense suggests that there is a causal nexus between Assassin A's shot, and the Queen's death: a bullet travelled from Assassin A's gun and entered the Queen's heart, causing it to stop beating. In short, common sense says that Assassin A killed the Queen. Unfortunately, the but-for test disagrees. But for Assassin A's shot, would the Queen have died? To prove causation, the but-for test requires a negative answer; yet we cannot give a negative answer, because Assassin B is also a crack shot and was taking aim from behind another grassy knoll at just the moment that Assassin A shot.

It is worth making a small detour to anticipate a common response to this problem. If Assassin B had shot the Queen, then she would have died a little later, the bullet would have come at a slightly different angle, and so forth. Can these details not be employed to salvage a sophisticated version of the but-for test? Despite some heroic

\footnotetext{
${ }^{5}$ David Lewis, Causation, 70 Journal of Philosophy 556-567 (1973); DAVID LeWis, Philosophical Papers, Volume II (1986) esp. Postscript E to "Causation". ${ }^{6}$ Cork $v$ Kirby Maclean Ltd [1952] 2 All ER 402; Barnett $v$ Kensington and Chelsea Hospital [1969] 1 QB 428. Many other authorities could be cited.
} 
efforts, ${ }^{7}$ the philosophical literature on the topic suggests that the prospects are dark. ${ }^{8}$ In particular, such a response requires that a given effect would be different - even if ever so slightly - had it had a different cause from the one it actually had. As a fully general proposition, this is false. If I press the button which arms my alarm clock, not knowing that my wife has already pressed it, then my press is not a cause of the alarm going off the next morning. The circuits were already connected; my press just moved some bits of plastic inside the clock. But the time and manner of the alarm's going off - at 7am, loudly - are just as they would have been had my wife not pressed and had my press instead been the cause. That is rather the point of alarm clocks. ${ }^{9}$

The inadequacy of the but-for test in cases of causal redundancy illustrates how satisfaction of the factual causation element of liability is not a purely factual matter. Faced with a case of causal redundancy, what is a court to do? Obviously, set aside the but-for test, and decide on some other basis whether a causal nexus exists. What this shows is that the decision to employ the but-for test, or any other test, for factual causation, is a legal decision.

That this is a legal decision is borne out by the leading authority on causation in English tort law at time of writing, ${ }^{10}$ which lays down guidelines on the circumstances

\footnotetext{
${ }^{7}$ David Lewis, Causation as Influence, in CAUSATION AND COUNTERFACTUALS 75106 (J. Collins, N. Hall, \& L. A Paul eds., 2004).

${ }^{8}$ John Collins, Preemptive Prevention, in CAUSATION AND COUNTERFACTUALS 107-117 (J. Collins, N. Hall, \& L. A Paul eds., 2004); Jonathan Schaffer, Trumping Preemption, in CAusation And Counterfactuals 59-73 (J. Collins, N. Hall, \& L. A Paul eds., 2004).

${ }^{9}$ Alex Broadbent, Reversing the Counterfactual Analysis of Causation, 15 INTERNATIONAL JOURNAL OF PHILOSOPHICAL STUDIES 169-189, 177 (2007); see also the Smart Rock example in Ned Hall, Two Concepts of Causation, in CAUSATION AND Counterfactuals 225-276, 237 (J. Collins, N. Hall, \& L. A Paul eds., 2004). ${ }^{10}$ Fairchild v Glenhaven Funeral Services Ltd \& Others [2003] 1 AC 32.
} 
in which the approaches to situations presenting conceptual or evidential difficulties for the proof of causation ought to be applied. ${ }^{11}$ The existence of such an authority (as well as its content) suggests that it is a matter of law which test ought to be used to establish factual causation. If that is so, then, as Wex Malone argues, ${ }^{12}$ satisfaction of that element of liability cannot be said to consist in a matter of pure fact. (This is so even if the test selected in a given circumstance tests for a matter of pure fact.) For the facts could be the same, and the law make a different recommendation about which test to use, yielding a different result. Again, that this is possible is borne out by a study of case law in this area, which shows the courts changing their minds - or at least evolving in their thinking - about how to treat cases. ${ }^{13}$ This is perfectly normal for a legal system based on precedent. But it shows that the legal question of whether a certain defendant's breach is a cause in fact can be answered differently, due to a difference in law but without disturbing facts. Thus it is hard to see how so-called factual causation, qua element of liability, can be purely a question of fact.

Wright does, of course, address Malone's line of argument. Yet it is hard to see what possible defence Wright has, in the absence of an adequate account of factual causation. As long as a fully adequate universal test for factual causation eludes us, and that is likely to be a long time yet, it will remain for courts to decide which of a number of tests for factual causation to apply - or, indeed, to apply no test at all, or to devise a new test. And as long as the courts choose between tests in this way, the

\footnotetext{
${ }^{11}$ In particular addressing the tension between Wilsher $v$ Essex Area Health Authority [1988] 1 All ER 871 and McGhee v National Coal Board [1973] 1 WLR 1 (HL). ${ }^{12}$ Wex Malone, Ruminations on Cause-In-Fact, 9 STANFORD LAW REVIEW 60-99 (1956).

${ }^{13}$ Again this is well illustrated by the tension between Wilsher $v$ Essex Area Health Authority [1988] 1 All ER 871 and McGhee v National Coal Board [1973] 1 WLR 1 (HL), subsequently resolved by Fairchild $v$ Glenhaven Funeral Services Ltd \& Others [2003] 1 AC 32.
} 
outcome of the inquiry is partly determined by the law, through the decisions of the courts.

\section{Is Factual Causation Fundamental?}

One way to reply to the foregoing argument is as follows. Granted, satisfaction of the element of liability called "factual causation" is partly a matter of law. Nevertheless, there is a real distinction between the objective facts about what causes what, and various judgements we might make about which of those facts is relevant in a given case. This is the fundamental reason for a distinction between factual causation and legal causation, as different elements of liability (the latter perhaps being an umbrella including more than one distinct element, reflecting different sorts of relevance considerations). In this section and the next I will argue that this, more fundamental basis for the standard implementation of the fact/law distinction in the causal inquiry also fails. This section will present difficulties for identifying a stable underlying notion of factual causation, shorn of relevance considerations; and the next will concern the inadequacy of analysing those relevance considerations as non-causal, purely legal liability limiters, under the umbrella of legal causation.

It is clear that causal judgements, whether in legal contexts, explanatory contexts, or elsewhere, almost always involve relevance considerations. In the broadest possible sense, the Big Bang might be considered a cause of everything that happens: it features in the causal history of every event we know of. Yet the Big Bang is rarely mentioned when we discuss the causes of particular events. We might admit that the 
relevance considerations excluding the Big Bang from daily chit chat may be interesting and important, but we might insist that they have nothing to do with causation itself: "metaphysical fluff", as the philosopher David Armstrong once remarked. On this view, the element of liability we call factual causation is concerned with establishing hard causal facts, not with fluffy relevance considerations. If we want to group these considerations together at all, perhaps we should do so under the head of legal causation (or proximate cause, remoteness of damage, or whatever other phrase suggests itself). On this view, the distinction between factual causation and legal causation as elements of liability remains important even if purism about the factual element fails for the reasons given in the previous section. The importance of the distinction is to emphasise the factual element of the causal inquiry is still concerned with identifying causal facts - even if, regrettably, the outcome of that inquiry is partly a matter of law, due to our confusion about precisely how to identify causal facts.

This line of thought receives support from contemporary philosophical approaches to causation. It is widely accepted among philosophers that there is a "fundamental notion" of causation, even if in casual talk we usually restrict our attention to those causes in which we are interested for whatever explanatory, moral, or indeed legal purposes we might have. According to this widely held view, as far the fundamental notion goes, this selective activity amounts to "invidious discrimination"14 which we have "philosophically speaking, no right" to make. ${ }^{15,16}$ This distinction is a close

\footnotetext{
${ }^{14}$ Lewis, supra note__ at 162.

${ }^{15}$ John StUART Mill, A System OF Logic, Ratiocinative And Inductive 237 (Eighth ed. 1887).

${ }^{16}$ The Mill-Lewis line is also discussed in Jonathan Schaffer, Contrastive Causation, 114 Philosophical ReVIEW 297-328, 342-3 (2005).
} 
parallel of the distinction in law between factual and legal causation. Just because we can't exactly say what this fundamental notion of causation amounts to, the argument goes, it hardly follows that we should abandon it altogether. Likewise, just because we cannot devise a legal test for factual causation, it hardly follows that we should abandon any factual element in the causal inquiry. It only shows that we need to be conscious of the limitations of our legal tests.

However, there are two obstacles to legal theory simply adopting the assertive stance of the philosophers. First, as H.L.A. Hart and Tony Honoré argue, the law needs to answer to common sense in a way which philosophers - rightly or wrongly - seem not to feel they need to. The concept of causation which the law uses and applies is derived from common sense, and ultimately answers to common sense. This "shared concept" claim is extremely plausible, ${ }^{17}$ provided it is not understood as the obviously false claim that the causal judgements made by common sense are exactly those made by law, and vice versa. The claim, rather, is that common sense and legal judgements about causation apply what is broadly the same concept, even if the legal application of that concept becomes technical. Another way to put the point is that, whatever the technicalities, the subject remains recognisable as pertaining to what we would ordinarily call causation. To that extent, the law and common sense share a concept of causation, and anyone who denies it must provide a better explanation of the curious fact that the law uses the ordinary word "cause".

That causal judgements in law answer to common sense presents a special difficulty for legal theorists who wish to cite this orthodox philosophical view of causation in

${ }^{17}$ Peter Lipton, Causation Outside the Law, in JuRISPRUdENCE: CAMBrIDGE ESSAYS 127-148 (H. Gross \& T. R Harrison eds., 1992). 
support of a distinct factual-causal element of liability. For our ordinary causal judgements simply do not have a corresponding distinct factual element, which might form the basis of our legal judgements about what counts as a cause in fact.

Extremely commonly, we pick out certain causes from among other causally relevant events. For example, I cite the late train as the cause of my arriving late at a meeting. I do not mention the presence of oxygen, nor my birth, even though but for either I would not have arrived late at the meeting. Naturally, we could interpret my claim that the late train caused my late arrival to mean that the late train was the most salient or relevant cause, yet not the only one. But if that is what I meant, it is strange that that is not what I said. The same goes for every singular causal statement ever made, since every one of them fails to mention all the but-fors of the effect in question (through ignorance if nothing else). We could insist that every causal claim of the form " $X$ is the cause of $Y$ " is strictly speaking false, and means merely that $X$ is an especially salient cause of $Y$ for present purposes. But this interpretation is imposed on, not suggested by, common sense and talk.

A related point is that taking a purely factual notion of causation as conceptually prior is misguided, with regard to our ordinary use of causal concepts. Normally, when we say of an event that it is the cause, we regard it as the cause from the start, and we may then come to learn more about the other causally relevant events. ${ }^{18}$ The procedure advocated by the purist about factual causation in law is the opposite way round, however: first identifying causally relevant events, and then asking whether they amount to causes for present, legal purposes. This reversal of the order in which

${ }^{18}$ H.L.A. HART \& A. HonORÉ, CAUSATION IN THE LAW 22-25 (Second ed. 1985). 
we commonly proceed threatens to undermine the common sense basis of legal judgements.

The second reason that legal theorists ought not adopt the assertive stance orthodox among philosophers is that there are philosophers who dispute the orthodoxy, and their point of dispute has special relevance to the law. Jonathan Schaffer, for example, points out that the extreme predictability of our supposedly invidious judgements about "the" cause amounts to "the sort of stable intuition that philosophers normally treat as data rather than rubbish" ${ }^{19}$ He doubts whether it is possible to arrive at a satisfactory analysis of factual causation, stripped of selective judgements of explanatory, moral, legal, or other kinds of relevance. He writes, “...it is not obvious that we have any such concept... Or at least, it is not obvious that our intuitions about causation can provide any evidence concerning this 'broad and nondiscriminatory concept', if our intuitions are shot through with selection effects". ${ }^{20}$

This is a problem for a legal theorist who hopes to rely on a philosophical consensus, since there is no such consensus, even if there is a prevailing view. But more specifically, the reasons given by the dissenters are of particular concern from a legal perspective, if it is accepted that legal judgements about causation ultimately answer to common sense. If, as Schaffer claims, the common sense notion of causation is shot through with selection effects, then it is hard to see how a legal notion of factual causation, devoid of selection effects, could answer to the common sense notion. ${ }^{21}$

\footnotetext{
${ }^{19}$ Schaffer, supra note__ at 343 .

${ }^{20}$ Jonathan Schaffer, The Metaphysics of Causation, STANFORD ENCYCLOPEDIA OF PHILOSOPHY (2007), http://plato.stanford.edu/entries/causation-metaphysics/.

${ }^{21}$ Other philosophical defences of selective notions of causation include C.J. Ducasse, On the Nature and the Observability of the Causal Relation, 23 THE JOURNAL OF
} 
To illustrate the latter point, and to provide a more positive argument for my case that a distinct notion of factual causation is untenable, let us run through a simple imaginary example. Jane is walking home from the pub, extremely drunk. She is walking on the pavement of a public highway, putting her in breach of a duty imposed by the laws of her land, which are like the laws of England except for the simplifying assumption that being excessively drunk on the pavement automatically puts you in breach of a duty to other road users. A car driven by Richard swerves off the road and hits Jane. She is injured, and Richard's car is damaged.

Clearly, common sense holds that both forms of damage are Richard's fault, and not Jane's; and we would naturally express this by saying that it was Richard's breach of duty, and not Jane's, which caused the damage. However, both of their breaches satisfy the but-for test with respect to the injury. But for Richard's swerve, there would have been no damage; but for Jane's drunken walking on the pavement, there would have been no damage. This appears to provide Richard with a claim, in respect of the damage to the front of his car, and a counter claim of contributory negligence, in respect of Jane's claim against him for her injuries. Yet surely, neither Richard's claim nor his attempt to secure a contribution from Jane ought to succeed: Jane's drunkenness had nothing to do with either form of damage.

PhILOSOPHY 57-68 (1926); Lipton, supra note___ Peter Menzies, Causation in Context, in Russell's Republic Revisited: CAUSATION, Physics, AND the CONSTITUTION OF REALITY 191-223 (Huw Price \& Richard Corry eds., 2007); Alex Broadbent, The Difference Between Cause and Condition, in press ProcEEDINGS OF THE ARISTOTELIAN SOCIETY (2008). 
An argument might be attempted on just this basis - that Jane's drunkenness played no part in the damage. Of course that is true, but the question is whether it can be captured by a legal notion of factual causation. At least on the but-for test, it cannot. We might try to argue that but for Jane's drunkenness, the damage might still have occurred, because Jane could still have been walking, but sober. This is not a principled argument, however: we might just as well argue that but for the walking, the injury might still have occurred, because Jane could still have been drunk, but in the pub. The breach of duty consisted in doing both at once; and the but-for test gives a different result depending which we apply it to.

If, as I am assuming, we wish to find that Jane's being drunk on the highway is not a cause of her own injury and the damage to Richard's car, the proponent of the but-for test must hope that Jane's breach is not a cause in law. No doubt the court would find accordingly, but three points of dissatisfaction are worth noting. First, the doctrine of novus actus interveniens cannot readily be applied to the case. It is hard to see Richard's swerve as a novus actus, breaking the chain of causation; after all, it occurred at the instant of the damage, and was indeed an essential part of the cause of the damage. More generally, the distinction between acts of third parties which follow naturally and therefore fail to be novus acta is suspect, as was noted in the forceful dissenting opinion of Blackstone $\mathrm{J}$ in the venerable case of Scott $v$ Shepherd. In that case, a lighted squib was thrown onto a market stall and then hurriedly thrown on by several successive panicking stall-holders before exploding in the plaintiff's face. The majority held that the stall-holders throwing on the lighted squib in those circumstances did not amount to a novus acta: the mischievous person who lit the squib in the first place caused the damage despite the intervening acts. Dissenting, 
Blackstone $\mathrm{J}$ asks on what principled grounds this differs from a case where a football is tossed into the street and kicked by a hundred people before breaking a tradesman's window. ${ }^{22}$ Even if we feel that the outcome of the case is just, Blackstone's demand for a principled account of what counts as a novus actus is compelling, and the case law since 1773 has done little more than the other judges' opinions did to satisfy that demand. ${ }^{23}$ Moreover (to forestall an obvious objection) tortious liability can persist where the novus actus of a third party is itself tortious, as our Richard's swerve is. ${ }^{24}$

Second, it can hardly be said that the damage is too remote from Jane's breach, if remoteness comes down to reasonable foreseeability. ${ }^{25}$ After all, it is presumably because damage of just these kinds is reasonably foreseeable when walking on a pavement of a highway, very drunk, that the duty Jane breached is imposed upon her.

Third, and more generally, even if the preceding two arguments are mistaken, and the doctrine of legal causation does have the resources to find that Jane's breach of duty was not a cause in law of the damage, there is a nagging source of dissatisfaction. It is the suspicion that this solution is not voluntary, but is forced upon us. Jane would disagree that her walking drunkenly on the pavement is in fact a cause of the damage, but that she is luckily relieved of liability because it is not a cause in law. She would rather deny it is in fact a cause of the damage in the first place. The legal doctrine of

\footnotetext{
${ }^{22}$ Scott $v$ Shepherd [1773] 2 B1 R 892. Legal scholars may be uneasy about the fact that this case concerns trespass, not negligence; indeed it considerably predates the tort of negligence as we now know it. Nevertheless, it is hard to see how that can excuse theorists of the modern tort of negligence from answering Blackstone's challenge, especially since the case remains an authority in negligence (albeit a venerable one).

${ }^{23}$ Cf. Knightley v Johns [1982] 1 WLR 349.

${ }^{24}$ Baker v Willoughby [1970] AC 467.

${ }^{25}$ The Wagon Mound (No 1) [1961] AC 388.
} 
cause in fact clearly contradicts this common sense intuition; it does not answer, as it ought, to common sense. The role of common sense in this argument is not to require that every causal and common sense judgement agree. Rather, the point is that insistence on a legal doctrine of factual causation, to the extent that it comes at the expense of the common sense notion of causation, comes also at the expense of deserving the name "causation". Divorced of common sense, factual causation becomes a purely legal doctrine.

\section{Legal causation}

In the previous section, I suggested reasons why it might be desirable to allow what we might broadly call relevance considerations into the factual causation element of liability. In this section I make the complementary argument, that these relevance considerations are not satisfactorily handled as purely legal restrictions on the causal facts. The basic reason is the same: that considerations of causal relevance are integral to our causal judgements, meaning neither makes sense when they are separated.

Legal causation might be characterised broadly as a class of legal doctrines which limit liability once a causal nexus has been established. But this characterisation is vague; and worse, it is not sufficient. The law has many mechanisms for limiting liability among causes in fact. In tort law, all the other stages of establishing liability could be seen as satisfying this definition: the imposition of a duty, the question of whether the duty was breached, and the question of whether the claimant suffered damage. A defendant who causes harm but who does not owe a duty of care, or who 
owes a duty but meets the standard of care, is not liable for the damage she thereby causes. A defendant who owes and breaches a duty and causes some effect on the claimant that fails to be a recognised form of damage is not liable. It will not do, then, to characterise legal causation as a set of legal doctrines limiting liability among causes in fact; such a characterisation would make the entire question of liability for negligence apart from cause in fact a question of legal causation.

Perhaps a more hopeful approach would be to specify the sorts of limitations which legal causation seeks to impose on liability among causes in fact. Legal causation arguably provides an entry point for policy considerations, and probably also for straightforwardly moral considerations which have little to do with policy and more to do with the rights and wrongs of a particular case. On this approach, all of our judgements of causal relevance would be akin to policy or moral considerations. That is, they would all be explained as the operation of certain other principles, which are not strictly causal in character.

For an example of how this might work, take the doctrine of remoteness of damage, which is governed by reasonable foreseeability. ${ }^{26}$ It is easy to identify a moral doctrine that remoteness of damage might be seen as instantiating. Consider the doctrine that ought implies can: there is no moral obligation on an agent to do something which the agent cannot do. And in order to be able avoid causing damage (other than by luck), you must be able to foresee it. Therefore an agent cannot be held morally responsible for unforeseeable damage (with some refinements to handle the crucial qualifier "reasonably" - itself a normative term). In this fashion, one aspect of

\footnotetext{
${ }^{26}$ Ibid.
} 
the doctrine of legal causation might be reduced to the operation of a principle of a quite different, non-causal sort, namely the moral principle that ought implies can.

The enormity of this reductive task ought not be underestimated, however. To take the particular example we have just toyed with, it is clear that the law does not always respect the moral ought-implies-can doctrine. For example, the law sometimes imposes a duty which defendants are unable to meet. ${ }^{27}$ Therefore the operation of the ought-implies-can principle is not sufficient to explain remoteness of damage; for circumstances exist in which that moral principle can be defeated, and does not dictate the law. The point can be generalised. On this reductive strategy, every single application of legal causation would need to be fully accounted for by the operation of some other, non-causal principle. No doubt some applications of legal causation are pure policy. But reducing every doctrine under that large umbrella to policy, moral or other non-causal considerations is an enormous task. Moreover, as we have just seen in the case of ought-implies-can, for every principle which is advanced, it is possible that an exception from some other part of the law might be found, which would show that the principle alone is not explanatorily sufficient. The complex and exceptionridden nature of the English common law makes this a rather likely prospect.

\section{A Contrastive Approach}

I now propose an analysis of factual causation which acknowledges the role of the law, and thus allows a better distinction between matters of fact and matters of law in

\footnotetext{
${ }^{27}$ E.g. on learner drivers in Nettleship v Weston [1971] 2 QB 691.
} 
the causal inquiry. The analysis is adapted from of a well-known and popular theory of explanation in the philosophy of science, namely the contrastive causal model of explanation developed in particular detail by Peter Lipton. ${ }^{28}$

To explain, scientists often cite a cause; but that is not a full picture. Some causes do not explain. I arrived late at the meeting because my train was late; that is the explanation. Among the causes of my late arrival is the step I took as I came through the door. That is not the explanation of my late arrival, however. Why not? Because, suggests the contrastive model, many of our why-questions are implicitly or explicitly contrastive. Often, we do not ask simply "Why $P$ ?" We ask instead, "Why $P$ rather than $Q$ ?" We ask, for example, why I arrived late rather than on time. And to answer a contrastive why-question, it is not enough to mention a cause of the fact, $P$. We must mention a causal difference between the fact, $P$, and the foil, $Q$. As Lipton puts it in his Difference Condition:

To explain why $P$ rather than $Q$, we must cite a causal difference between $P$ and not- $Q$, consisting of a cause of $P$ and the absence of a corresponding event in the case of not- $Q .{ }^{29}$

We must mention, for example, a difference between my arriving late and on time.

Either way, I would have stepped through the door. But in the case where I arrive on

\footnotetext{
${ }^{28}$ Peter Lipton, Inference to the Best Explanation (Second ed. 2004) esp. Ch 3; Peter Lipton, Contrastive Explanation, in EXPLANATION AND ITS LIMITS 246-266 (D. Knowles ed., 1990); see also David Lewis, Causal Explanation, in Philosophical PAPERS, Volume II 214-241 (1986); AdAM GARFInKLE, Forms OF EXPLANATION 28-41 (1981); BAS VAN FRAASSEN, THE SCIENTIFIC IMAGE 126-9 (1980).

${ }^{29}$ Lipton, supra note___ at 42.
} 
time, my train is not late; and in the actual case, my train was late. That is why my late train can explain why I was late rather than on time, while my stepping through the door cannot, even though both may be causes of my arriving late.

An important feature of the contrastive approach to explanation is the way it handles the context sensitivity of explanation. To adapt Hart and Honoré's example, the wife explains the husband's stomach pain by the fact he ate parsnips for dinner; while the doctor explains it by the fact the man has a stomach ulcer. ${ }^{30}$ The doctor and the wife need not be seen as disagreeing with each other, however, on the contrastive model. They are merely asking and answering different questions. The wife's question is, "Why did my husband get stomach ache this evening, and not yesterday or on many previous days?" The difference is that this evening, he ate parsnips for dinner. While the doctor's question is, "Why did this man get stomach ache, when many other men do not?" Eating parsnips is something that many other men sometimes do without getting stomach ache, so cannot explain this man's stomach ache; while a stomach ulcer is not something which many of those other, stomach-ache-free men have. Thus the doctor and the wife do not disagree; they are merely answering different questions.

Another feature of this model that I want to emphasise is the location of the distinction between objective (or factual) and subjective (or interest-relative) components of explanation. What counts as a good explanation depends, as we just saw, in part on who is asking, among other things. But surely it does not depend only on such things. It is, in part, an objective matter whether an explanation is satisfactory

\footnotetext{
${ }^{30}$ Hart and Honoré, supra note__ at 35-6.
} 
or not; if you are late, you cannot say anything that comes into your head by way of excusing yourself, and point in your defence to the interest-relativity of explanation. The contrastive model allows for both an objective and a subjective component of explanation. Explanation is subjective inasmuch as it is up to us what question to ask, and therefore what contrast to specify in our question. However, once a contrast is specified, it is a matter of objective fact whether a proposed answer satisfies the Difference Condition, and specifies a difference between the fact and the foil with which it is contrasted.

The handling of the objective/subjective distinction in the explanatory context is the key reason, as I see it, to seek to transpose a contrastive model to the causal inquiry in law. Our goal is to implement a clear distinction between matters of fact and matters of law. I have argued that the satisfaction of the element of liability called factual causation is not a purely factual matter. Therefore, if the fact/law distinction is to be preserved, that distinction must be identified within the scope of that element of liability. The contrastive approach suggests a precise way to make this distinction. In the explanatory context, it is a subjective matter what contrast is picked, but an objective matter whether a putative explanation satisfies the Difference Condition with respect to that contrast (whether it is a causal difference between fact and foil). Likewise, a contrastive analysis of the fact/law distinction in the causal inquiry would make it a matter of law which contrast was legally appropriate, but a matter of fact whether the wrongful act in question amounted to a difference between the instant case and the legally appropriate foil where the harm does not occur.

That is the idea in outline, and this is the proposed analysis: 
Contrastive Condition on Causation in Law: For a defendant's breach of duty to satisfy the causal element of liability with respect to a given harm to the claimant, the breach must be a difference between the instant case, and the legally appropriate foil where the claimant did not suffer that harm.

The distinction between fact and law is crystal clear. It is a matter of fact whether the defendant's breach of duty is a difference as required between the instant case and the foil with which it is contrasted. But what contrast is appropriate - what foil we should set against the facts of our case - is a matter of law.

Let me illustrate how the contrastive approach is supposed to work using the imaginary example discussed previously. The cause of Jane's injury and the damage to Richard's car, for the purposes of the law, must be a difference between the instant case where this damage occurs, and the legally appropriate foil where it does not. That foil is one in which Jane walks home, drunk and thus in breach of duty. Jane's breach of duty thus occurs in both fact and foil, so cannot be the cause of the injury, at least for legal purposes. Richard's swerve, however, does not occur in the legally appropriate foil where the damage is averted. Thus it is a difference between fact and foil, so satisfies the Contrastive Condition.

To complete this account, we need more information about what makes a foil legally appropriate. What justifies the claim that, in the legally appropriate foil where the damage is averted, Jane's breach still occurs while Richard's does not? What is to 
stop Richard's lawyer insisting that the appropriate foil is one where Jane stays off the streets, while Richard still swerves? A foil is just a hypothetical scenario in which the damage claimed for does not occur; there will generally be more than one way that any given damage might have been avoided, and thus more than one candidate foil. Whether a given breach of duty meets or fails the Contrastive Condition depends on which foil is chosen as legally appropriate. So the contrastive approach requires an account of what it is for a foil to be legally appropriate.

(It might be objected that the Contrastive Condition wrongly includes causes when the tortious act resulted in a benefit to the claimant. For example, a fraudulent doctor chances upon an effective technique unknown to modern medicine, and the patient dies a month later than she otherwise would have, had she received conventional treatment. The fraudulent doctor's act seems to satisfy the Contrastive Condition, since it is a difference between the instant case and the (presumably) legally appropriate foil where the patient receives conventional medical treatment - and dies a month earlier. ${ }^{31}$ In response, I say that the Contrastive Condition pronounces correctly: the fraudulent doctor did cause the patient to die a month later than she otherwise would have. The case against the doctor surely will not fail on causation. Rather, it will fail on another element of liability: damage. Dying later than one otherwise would have is not a recognised form of damage; indeed, it would usually be regarded as a benefit. The Contrastive Condition correctly identifies the doctor as the cause of this benefit.)

\footnotetext{
${ }^{31}$ I am grateful to Jonathan Schaffer for this counterexample.
} 
Contrastive accounts of causation have been applied to the law before. What have they had to say about this question? The answer is, very little: they have not faced this problem squarely. Lipton, in a discussion of Hart and Honoré's work, suggests that much of the ordinary concept of causation can be captured more elegantly and more accurately by his contrastive model than by Hart and Honoré's own proposal. ${ }^{32}$ But he does not tell us how contrasts are generated. Schaffer discusses causation in the law in the same breath as the role of causation in moral judgements, and suggests that, in the legal case, "the appropriate contrasts are codified in the law". ${ }^{33}$ Again, this does not tell us exactly how contrasts are picked. In fact, as a claim about the explicit structure of the law, it is false, since the law does not have an explicitly contrastive causal inquiry, and so does not explicitly codify appropriate contrasts. Such claims are only plausible if taken to concern the deep rather than the explicit structure of legal thinking about causation. This does not mean that accounts such as Lipton's and Schaffer's escape the need to say something about the source of legally appropriate contrasts, but it may explain why that need might have been overlooked. My argument, on the other hand, is that there is something wrong with the explicit structure of causal judgements, and that they can be fixed by giving them an explicitly contrastive structure. This brings me right up against the need for an account of the legally appropriate contrast. ${ }^{34}$

\footnotetext{
${ }^{32}$ Lipton, supra note

33 Schaffer, supra note__ at 345 Schaffer's theory differs from Lipton's, proposing " $c$ rather that $C^{*}$ causes $e$ rather than $E^{*}$ " as the underlying form of causal claims. Lipton's contrastive theory specifies a contrast for the effect only, however, which is then supposed to determine (or narrow down) the selection of the cause.

${ }^{34}$ Contrastive accounts of explanation in the philosophy of science do not provide inspiration here either. Contrastive explanations are answers to contrastive whyquestions, and explaining why we ask the questions we do is "not part of providing a model of explanation, as that task has traditionally been construed" - Lipton, supra note at 46 .
} 
Since the foil is supposed to be legally appropriate, it would seem natural to seek a solution in other elements of liability, especially (in the context of negligence) to duty. In particular, I suggest we should ask of a candidate foil whether it just observation of the defendant's duty, or whether the foil requires the duty to be met in a particular way. Richard's lawyers (accusing Jane) will struggle with this question. The foil they propose is one where Richard still breaches his duty, by swerving, but Jane meets her duty of care, by staying off the street in her drunken state. However, this foil requires more of Jane than that she merely observes her duty. She could equally have done that by drinking less, but being exactly where she actually was when Richard swerved off the road. So although Jane's breach is a difference between the foil proposed by Richard's team and the actual case, the foil proposed by Richard's team is not one in which Jane merely observes her duty, but one where she observes it in a particular way. The law does not require that Jane observe her duty in this particular way. Thus the foil is not legally appropriate for establishing that the breach of this duty caused the damage.

On the other hand, by not swerving, Richard would merely have met his duty to drive with due care and attention. He is not required to meet this duty in any particular way. Thus the foil in which Richard does not swerve is legally appropriate, and Richard's swerve meets the Contrastive Condition.

(It might be objected that Richard could have met his duty by having an unexpected stroke five seconds before his swerve, and thus that the proposed foil does after all require him to observe his duty in a particular way - by remaining conscious and not having a stroke. But to introduce such a stroke is to depart from the facts of the case 
in a gratuitous way. So we must require that legally appropriate foils not depart gratuitously and frivolously from the facts of the case. The requirement of no gratuitous departure is hard to spell out, but is not peculiar to the contrastive approach; it is also necessary to make the but-for test work. Otherwise, who knows what would have happened but for the defendant's breach? In practice it is easy enough to spot a gratuitous departure; and if this is intended as a theoretical objection then there is a similar problem for the but-for test.)

Accordingly I propose the following restriction on legally appropriate foils.

Legally appropriate foil. A foil is legally appropriate for proving that a defendant's breach was a cause of damage only if the foil involves the mere meeting of the defendant's duty of care (not the meeting of the duty in some particular way beyond what the duty itself requires).

To illustrate with a real life example, in The Empire Jamaica the owners of a ship hired an unlicensed pilot, who fell asleep on duty. The ship crashed. It was held that, although hiring an unlicensed pilot was a breach of duty, the breach did not cause the damage: the pilot was generally competent and there was no reason to suppose that having a license would have kept him awake. This is a good case for the contrastive approach, because as Schaffer puts it:

[The owners'] sending the ship to sea without licensed officers (what actually transpired) rather than with licensed officers (the lawful course) was not the cause of collision rather than safe passage. For the pilot's lack of license did 
not bear on his general competence and so made no difference to the collision. $^{35}$

But Schaffer's account does not explain why this lawful course is the legally appropriate foil. Another lawful course would be for the ship's owners not to send their ship to sea at all. If that were the legally appropriate foil, then sending the ship to sea without licensed officers would be a difference between fact and foil. Without an explanation of why the lawful course identified by Schaffer is the legally appropriate foil, the contrastive approach cannot fully answer the question to which it is addressed.

We can develop Schaffer's line of analysis by applying my proposed Contrastive Condition. The claim against the owners could only succeed if sending the ship to sea with an unlicensed pilot was a difference between the facts of the case and the legally appropriate foil. But the owners could have met their duty by ensuring their pilot was licensed before sending the ship to sea, or by not sending it to sea at all. For the plaintiffs to satisfy the Contrastive Condition, they would have to propose a foil in which the duty is observed by not sending the ship to sea. But the owners could have observed their duty in ways not covered by the plaintiffs' proposed foil, by hiring a licensed pilot. This way of observing the duty cannot be included in the plaintiffs' foil because there is no reason to suppose that this officer, licensed, or another licensed officer, would have been any more wakeful. The actual argument of the case appears to have turned on this point, which is consistent with the Contrastive Condition: had the plaintiffs' argument succeeded, that would have shown that their proposed foil did

\footnotetext{
${ }^{35}$ Schaffer, supra note at 345.
} 
not pick and choose among ways for the defendants to meet their duty, and thus that it was legally appropriate and that the Contrastive Condition was satisfied. However, since there were ways for the defendants to meet their duty that cannot be included in the foil (without gratuitous departure from the facts), the foil does not contain a mere meeting of the defendant's duty. So the foil is not legally appropriate, and the plaintiffs fail to establish that the owners' breach of duty causes the damage, according to the Contrastive Condition.

The final point I want to make about the proposed Contrastive Condition is that it is a necessary and not a sufficient condition for a cause in fact. Establishing that an event is a difference between the fact and the foil is not enough to establish that it is the cause, for legal purposes. For example, among the differences between the case where Jane was injured and the hypothetical case where she was not, is a slightly greater heating of the tyres on Richard's car, due to increased friction with the road brought about by a sharp change of direction.

This is not a serious drawback for the use of the Contrastive Condition. It is a difficult necessary condition to satisfy, and whatever other necessary conditions need satisfying are obvious enough in practice. Some differences between fact and foil will be eminently non-causal: for example, the triangles we would get if we drew straight lines between Richard, Jane and the pub at a time just after that at which the accident in fact occurred. Other differences will be causal but will not attract liability, such as the heating of the tyres. The tyres are not legal persons, so cannot be liable. More generally, the law can make formal stipulations about the burden of proof. The burden of showing that the defendant's action is a difference between the fact and the legally 
appropriate foil (and thus the task of proposing a legally appropriate foil) would surely lie with the claimant, since she who asserts proves. If this were established, it would be for the defendant to rebut the presumption that her breach was the cause, by arguing that although it was a difference between fact and foil, it was yet not a cause for legal purposes because of the operation of some other principle - such as the principle which saves the tyres from liability. Exceptions of this sort would be rare, because any applicable principles would probably have come into play long before the discussion of causation; nobody tries to sue tyres. Therefore the Contrastive Condition on Causation in Law, despite being a necessary and not a sufficient condition, seems suitable to be employed by a claimant seeking to prove causation: I suggest a defeasible presumption that an act satisfying the Contrastive Condition counts as a cause. This presumption still leaves work for policy considerations, and other doctrines which we might class under the umbrella of "legal causation". For example, a doctor in breach of duty might be found to have caused harm, but might escape liability for fear of encouraging "defensive medicine". Nothing I have said is intended to touch considerations of this sort. ${ }^{36}$

\footnotetext{
${ }^{36}$ I am grateful to Roderick Bagshaw, John Clifford, Vanessa Heggie, Matthew Kramer, Amit Pundik, Nicky Reeves, Jane Stapleton, an anonymous referee and especially Jonathan Schaffer for their help. I am also grateful to audiences at the Hughes Hall Centre for Biomedical Science in Society, the Edinburgh Legal Theory Research Group, and the Edinburgh Festival for Legal Theory. I am grateful to the PHG Foundation for supporting part of this research.
} 